mentais - as célebres Gedankenexperimente. A elas recorrem, todavia, com maior consciência e consistência os teóricos da física do nosso século, de Einstein a Heisenberg. Trata-se de experiências que se não podem realizar, por manifestas dificuldades técnicas, das quais se "imagina" o desenvolvimento por recurso a todos os conhecimentos que se possuem do problema, enquadradas num projecto muito preciso e numa discussão que se reveste de toda a seriedade e credibilidade (ver, por exemplo, ref. 18, Apêndice XI, pp. 442 ss., ou A. Koyré, Galileo's Treatise "De motu gravium": the use and abuse of imaginary experiment in Revue d'Histoire des Sciences, 13 (1960), pp. 197-245, reproduzido in Methaphysics and Measurement:
Essays in the Scientific Revolution, Ed. Chapman \& Hall, Londres, 1968 , cp. III).

(15) - H.R. Pagels, O. Cit., pp. 30,66

(16) - Citado in Editor's Outlook, J. Chem. Educ., 8, 209 (1931).

(17) - V. Kraft, The Viena Circle; the origin of neo-positivism (Greenword' Press, London, 1953).

(18) - K.R. Popper, The Logic of Scientific Discovery (Basic Books Inc., New York, 1959).

(19) - Cit, in H. Margeneau, The Nature of Physical Reality - A Philosophy of Modern Physics (McGrawHill Book C.ie, N.Y., 1950) pg. 99.

\title{
A regra do octeto
}

De acordo com Kossel [1] quando dois elementos se combinam para formar um composto, dá-se uma troca de electrōes de modo que ambos adquirem o número de electrões do gás "inerte" mais próximo. Contudo nem todos os compostos são iónicos, pelo que Lewis veio, quase simultaneamente, a contemplar a formação de compostos covalentes através da partilha de pares de electrões [2]. Esta veio dar origem à regra do octeto, também aplicável aos compostos iónicos. Se bem que Lewis reconhecesse que nem todos os compostos obedecem à regra do octeto, na divulgação da obra isto não foi normalmente tomado em consideração. Actualmente um grande número de livros de Química Geral acentuam a regra do octeto [3-4-5] e discutem, imediatamente a seguir, algumas excepçס̃es. Alguns contrariam o ensino da regra do octeto [6], pelo menos na parte inicial de um curso de Química. Historicamente os gases "inertes" tiveram um papel muito activo na formação deste conceito; não eram reactivos, o que se atribuia à sua configuração electrónica, com o octeto exterior de electrões, $\mathrm{O}$ facto de se saber agora que, de facto, alguns gases raros formam compostos estáveis retira, em parte, uma razão histórica da regra.

O número de excepçð̃es existente, desde os simples $\mathrm{BeCl}_{2}$ e $\mathrm{AlCl}_{3}$ (que se podem explicar razoavelmente) até aos mais complicados $\mathrm{ICl}_{3}$ (com 10 electrões exteriores em volta do átomo central) e $\mathrm{SF}_{6}$ (com 12 electrões), são bastantes, para que a regra do octeto não seja ensinada com grande relevância [7].

A regra do octeto leva-nos a escrever a estrutura do oxigénio incorrectamente, quando o poderíamos escrever como um dirradical, com sete electrões em volta de cada átomo de oxigénio.

Aparecem ainda outros problemas quando se pretende escrever as estruturas de Lewis para $\mathrm{NO}_{3}^{-}$e $\mathrm{NO}_{2}^{-}$, prestando atenção à regra do octeto. Aqui torna-se imperativa a introdução do conceito de ressonância (figura 1)<smiles></smiles>

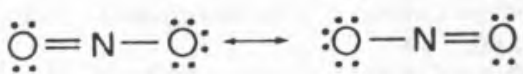

o que não seria necessário no caso de não se prestar atenção àquela regra (figura 2). $\mathrm{O}$ facto destas últimas estruturas não reflectirem o carácter parcial duplo da ligação N-O é de menor importância, dado que o conceito de ligação dupla e simples nem sempre se reflecte na forma de escrever as ligações [8].

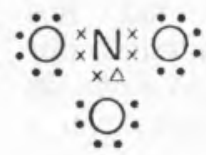

ou<smiles>O=NN(O)O</smiles>

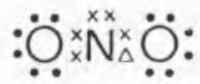

ou<smiles>ONNO</smiles>

Fig. 2

A experiência mostra-nos que a regra do octeto se torna confusa para os alunos, particularmente quando se começa a falar das excepções e dos ajustamentos necessários através da ressonância.

Considera-se que a regra do octeto foi uma regra prática da Química durante algum tempo, mas que é agora desnecessária e confusa para a maior parte dos alunos.

Sugere-se que ela seja mencionada no seu contexto histórico e apenas depois dos alunos terem adquirido alguns conhecimentos mais profundos sobre ligações químicas.

1 - Kossel, W., Ann. Phys. 49, 229 (1916).

2 - Lewis, G.N., J. Amer. Chem. Soc. 38, 762 (1916).

3 - Russel, J.B., Química Geral, McGraw-Hill do Brasil, 1982.

4 - Mahan, B.H., Química - Um Curso Universitário, Edgard Blücher, São Paulo, 1984.

5 - Brescia, F.; Arents, J.; Meislich, H.; Turk, J., Fundamentals of Chemistry, Academic Press, 1980.

6 - McClellan, A.L., Guia do Professor para Química - Uma Ciência Experimental, Fundação Calouste Gulbenkian, Lisboa, 1984. 7 - Snadden, R.B., Education in Chemistry, 81 (1987).

8 - Sandström. J., Endeavour, 37.111 (1984). 